\title{
EPILEPSY IN NIGERIA - A REVIEW OF ETIOLOGY, EPIDEMIOLOGY AND MANAGEMENT
}

\author{
A. Ogunrin Olubunmi B.Sc, MBChB, FWACP \\ Consultant Neurologist, Department of Medicine, University of Benin \\ Teaching Hospital, Benin City
}

\begin{abstract}
Epilepsy is a major public health issue especially in developing African countries. The etiologies and approach to management are significantly different in developed and developing countries, with infectious causes and treatment with phenobarbitone being the peculiarities of the developing subSaharan African countries. This review emphasizes the peculiar etiological considerations, epidemiology and treatment options of epilepsy in Nigeria, and also compares these with the practice of epilepsy management in other African and developed countries.
\end{abstract}

\section{INTRODUCTION}

Epilepsy is the most common non-infectious neurologic disease in developing African countries, including Nigeria ${ }^{1,2}$ and it remains a major medical and social problem ${ }^{1}$. Historically, epilepsy was believed to be a sacred disease that is the result of the invasion of the body by a god. It was thought that only a god could deprive a healthy man of his senses, throw him to the ground, convulse him and then rapidly restore him to his former self again ${ }^{3}$. The word 'lunatic' was first applied to sufferers of epilepsy as gods were thought to occupy heavenly spheres, one of which was the moon. In contrast, mad people were referred to as 'maniacs' whose madness was a result of invasion of the body by devils or evil spirits. In the Gospel according to Saint Mark ${ }^{4}$, it was a foul spirit that was cast out of the young man with fits. The 'Dictator Perpetuus' of the Roman Empire, the great Julius Caesar likely had epilepsy on the basis of documented four attacks that were probably complex partial seizures. Also, it is possible that he had absence attacks as a child and as a teenager. His son, Caesarion, and his great-great-great grandnephews Caligula and Britannicus also had seizures. The etiology of epilepsy in this Julio-Claudia family is probably linked to inheritance ${ }^{5}$.

This historical legacy has continued to influence public attitude to epilepsy making it a dreaded disease. These beliefs have resulted in patients with epilepsy (PWE) being ostracized, stigmatized and misunderstood. The social implications are serious. For instance, in Madagascar, patients with epilepsy are refused burial in the family grave ${ }^{2}$. In many African countries, the PWE is an out-cast ${ }^{6}$ as Africans believe that the disease results from visitation of the devil, effect of witch-craft, the revenge of an aggrieved ancestral spirit or consumption of something harmful in utero $^{7,8}$. Suicide or attempted suicide is not uncommon among Nigerians who suffer from epilepsy ${ }^{9,10}$. The patient with epilepsy is likely to drop out of school, lose his job, finds it 
impossible to marry, loses his wife or her husband, and be tormented to the extent of becoming a vagrant vagabond $^{2,9,10}$.

The remarkable issue raised by Hippocrates' famous treatise on the 'Sacred Disease' was his belief that epilepsy was not sacred, that the brain was the seat of the disease. In the latter half of the nineteenth century, Hughlings Jackson ${ }^{11}$ defined epilepsy on the basis of a neuronal theory. About three decades later, William Gowers ${ }^{12}$ observed a link between epilepsy and cognitive deterioration. He noted that defective memory, especially for recent acquisitions and weakened capacity for attention are frequently encountered cognitive impairments in epileptic patients. This observation was not novel as Tissot in $1770{ }^{13}$ in his 'Traite' de L`Epileptic' wrote that he had never seen a patient with epilepsy whose fits were not very rare not complaining about a weakening of memory.

\section{Definition}

According to the World Health Organization dictionary of Epilepsy, epilepsy is defined as a "chronic disorder of the central nervous system of various etiologies characterized by recurrent seizures due to excessive discharge of cerebral neurones. Single or occasional seizures as well as those occurring during an acute illness should not be classified as epilepsy ${ }^{14}$.

\section{Epidemiology}

At a conservative estimate, 50 million people worldwide have epilepsy with an annual incidence ranging from 20 to 70 cases per $100,000^{15}$ and the point prevalence of
0.4 to 0.8 percent $^{16}$. The incidence rates are highest in childhood, plateaus from the age of 15 to 65 years, and rise again among the elderly $^{15,16}$. Most patients suffering from epilepsy in African countries prefer anonymity and are reluctant to disclose their condition because of the stigma attached to the disease ${ }^{2}$. This factor affects the prevalence rates hence there is likelihood that most of the reported prevalence rates represent a 'tip of the ice-berg' as the chances of under-reporting are high. The prevalence rates of epilepsy reported in Africa are based on surveys of defined communities and hospital admissions.

The prevalence of epilepsy is particularly high in developing countries especially in Latin America and several African countries, notably Liberia, Nigeria and United Republic of Tanzania ${ }^{1}$ compare with the prevalence rates of between 4 and 6 per 1000 which have been reported among Caucasians ${ }^{16}$. In Nigeria, its prevalence, based on defined communities, varies from 15 to 37 per $1000^{3}$. However one of the early publications $^{17}$ on the prevalence of epilepsy in Nigeria reported a prevalence of between 8 and 13 per 1000 inhabitants in the urban communities of Lagos, but with a computed rate of 3.1 per 1000 . Osuntokun et $a l^{18}$ reported a prevalence rate of 5.3 per 1000 among the inhabitants of Igbo-ora, a community with comprehensive health facilities, with the highest age-specific prevalence ratio occurring below the age of 20 years i.e. within 5 to 14 years age group. This prevalence rate is lower than what obtains in most rural African communities (refer Table 1) and similar to that of Western countries. The lower prevalence rate is probably due to the improved health facilities in this community. In another 
community-based study, Longe and Osuntokun $^{19}$ reported a prevalence rate of 6.2 per 1000 among the residents of Udo, a rural Community of Edo-speaking people in Nigeria.

The age distribution in Nigerians appears similar to that described among the Caucasians. Between $70 \%$ and $85 \%$ of PWE have onset of seizures below 30 years of age $^{2}$. Osuntokun et al ${ }^{20}$ and Udofia ${ }^{3}$ noted that the onset in $68 \%$ of patients was in the first and second decades of life. Obembe and Ahmed ${ }^{21}$ confirmed this among children over 5 years of age with a prevalence of $82 \%$. Among adult Nigerians, a study reported a mean age of 21 years with dominance of partial seizures $(53.3 \%)^{22}$.

Most African studies reported a slight male excess ${ }^{2}$. It is thought that, in most parts of Africa, males more readily come to the hospital for socioeconomic reasons and hence predominate in the hospital populations. This pattern holds true for Nigerians with epilepsy. The male sex preponderance may also be due to occupational and social exposure to epileptogenic insults such as cranial trauma and alcohol.

Epilepsy tends to be more common in the lower socio-economic groups ${ }^{23}$. Shomansky and Glaser ${ }^{24}$ found an excess incidence of epilepsy among the poor blacks in United States of America. Several studies reported in Africa also confirmed a higher prevalence of epilepsy among rural dwellers ${ }^{2,25,26}$. These epidemiological findings are of importance as they imply that, at least part of the burden of the incidence of epilepsy can be solved by preventive methods to improve social health as certain risk factors have been identified to increase the prevalence of epilepsy. In a case-control study in which 155 Nigerian epileptic patients were compared with age and sex - matched controls, febrile convulsions and head trauma were significant risk factors for epilepsy, while childhood immunization was significantly associated with decreased prevalence ${ }^{27}$. Other studies have confirmed the importance of birth asphyxia, intracranial infections, hereditary factors and head injuries as important risk factors $1,2,28$. Many of these factors are preventable or modifiable and the introduction of appropriate measures to achieve this could lead to a substantial decrease in the incidence of epilepsy in developing countries.

Table I: $\quad$ Prevalence of epilepsy in Nigeria and other African countries

\begin{tabular}{|c|c|c|}
\hline $\begin{array}{l}\text { COUNTRY } \\
\text { LOCATION }\end{array}$ & $\begin{array}{l}\text { PREVALENCE } \\
\text { RATES/1000 }\end{array}$ & INVESTIGATOR \\
\hline Congo & 4 & Piraux (1960) \\
\hline $\begin{array}{l}\text { Bantus, } \\
\text { South } \\
\text { Africa }\end{array}$ & 4 & Bird et al (1962) \\
\hline Ghana & 4 & Haddock (1973) \\
\hline Uganda & 4 & Orley (1970) \\
\hline Zimbabwe & 7.4 & Levy et al (1964) \\
\hline $\begin{array}{l}\text { Ethiopia } \\
\text { (Rural) }\end{array}$ & 8 & Giel (1968) \\
\hline $\begin{array}{l}\text { Ethiopia } \\
\text { (Urban) }\end{array}$ & 5 & Giel (1968) \\
\hline Senegal & $3-8$ & $\begin{array}{l}\text { Collomb et al } \\
\text { (1970) }\end{array}$ \\
\hline Tanzania & 1 & Smartt (1959) \\
\hline Tanzania & 20 & $\begin{array}{l}\text { Jilek \& Jilek } \\
\text { (1970) }\end{array}$ \\
\hline Kenya & $10-18$ & Miyangi (1995) \\
\hline $\begin{array}{l}\text { Nigeria } \\
\text { Urban }\end{array}$ & $8-13$ & Dada (1970) \\
\hline $\begin{array}{l}\text { Nigeria } \\
\text { Rural }\end{array}$ & 5.3 & Osuntokun(1987) \\
\hline $\begin{array}{l}\text { Nigeria } \\
\text { Rural }\end{array}$ & 6.2 & $\begin{array}{l}\text { Longe and } \\
\text { Osuntokun(1989) }\end{array}$ \\
\hline
\end{tabular}

\section{Etiology}

Idiopathic epilepsy still remains the commonest in all age groups, though the frequency of symptomatic epilepsy progressively rises with age ${ }^{2}$. Idiopathic epilepsy constitutes 55 $60 \%$ of epilepsy reported in Nigerians ${ }^{2}$. In other parts of the world, about $30 \%$ 
of patients with seizure have an identifiable neurological or systemic disorder, and the remainders have either idiopathic or cryptogenic epilepsy ${ }^{29}$.

\section{Genetics}

Several studies conducted in recent times showed that inherited forms of epilepsy account for about $20 \%$ of all patients with epilepsy, particularly in children ${ }^{30}$. Although the premise that heredity plays an important role in epilepsy was first noted by Hippocrates in 450 B.C. in his treatise on 'The Sacred Disease' where he stated that, 'It is thus with regard to the disease called Sacred; it appears to me no more divine nor more Sacred than other diseases. Its origin is hereditary, like that of other diseases'. Now we know that epilepsy is a component of the phenotype in over 100 mendelian disorders, but the most common genetic epilepsies display a 'complex' non-mendelian pattern of inheritance. These include several well-defined syndromes such as juvenile myoclonic epilepsy (JME), absence epilepsy and benign childhood epilepsy with centrotemporal spikes. Many of the recessively inherited disorders of lipid and aminoacid metabolism may be associated with seizures ${ }^{31,32}$, for example in ceroid lipofucinoses and Tay Sach's disease, both commonly associated with myoclonic seizures. Other recessively inherited disorders like tuberous sclerosis ${ }^{33}$, neurofibromatosis and Lafora body disease are also associated with seizures ${ }^{32}$.

The basic neurobiological basis of these common familial epilepsies is entirely unknown but recent advances in genetics and molecular biology have provided new methods for investigation of human inherited diseases known only by their phenotype. Recently mutations in the subunit of the glycine receptor have been reported in patients with hyperekplexia, a neurological disorder with features in common with epilepsy ${ }^{30}$. The role of inheritance has been more extensively studied in typical absence seizures than in any other seizure type. Metrakos and Metrakos ${ }^{34}$ found generalised spike and wave activity in the eletro- encephalograms (EEG) of $37 \%$ of siblings of patients as opposed to $9 \%$ in the control group. Furthermore, a $50 \%$ risk of inheriting the gene for the spike and wave abnormality on the EEG of offsprings and siblings of patients, and a 12\% risk of actually having one or more seizures were reported ${ }^{34}$.

The role of genetics in primary generalized tonic - clonic seizures (GTC) has also been documented ${ }^{31,34}$. The mode of inheritance appears to be heterogenous, with both polygenic/ multifactorial, and unrecognized singlegene factors all playing roles. There is a well-documented relationship between primary generalized seizure type, particularly typical absence seizures, and primary generalized tonic - clonic seizures. Generalized tonic seizures commonly occur in patients with typical absence seizures. In addition, relatives of patients with typical absence seizures have a higher risk for GTC seizures as well as absence seizure than the general population ${ }^{34}$. Photosensitive epilepsy, a form of reflex epilepsy that is precipitated by flickering light and that occurs around puberty with a higher incidence in girls than in boys, has been reported to be familial $^{35}$. 
Although there is general agreement that genetic factors are important in generalized seizure disorders, partial seizures have been attributable mainly to acquired causes such as asphyxia, infection, trauma, tumor and haemorrhage ${ }^{1,18,36}$. Some workers had, however, reported the interaction of environmental and hereditary influences in partial seizures $^{32,34}$. Rimoin and Metrakos ${ }^{37}$ reported that patients who suffered brain insults and did not have seizures had a lower familial predisposition to seizures than those who did have seizures. Furthermore, $15 \%$ of siblings of children with complex partial seizures were reported to have had seizures.

The literature concerning the genetics of febrile seizures is voluminous and controversial. It is however generally agreed that there is an increased incidence of febrile seizures among the relatives of children with febrile seizures ${ }^{31}$. A positive family history for febrile seizures can be elicited in 25 to $40 \%$ of patients with afebrile seizures ${ }^{16}$.

There is scanty information available on genetic epidemiology of epilepsy in Nigerians, but there are reports of tuberous sclerosis among Nigerians with epilepsy ${ }^{28,33}$.

\section{Infections}

The commonest cause of symptomatic epilepsy remains central nervous system infections, mainly bacterial and viral meningitis, encephalitis, neurosyphilis, brain abscess and tuberculosis. These infections accounted for $10 \%$ to $20 \%$ of cases of epilepsy reported in Africa $^{2}$. Most of the acute presentations of seizures in the tropics, where health facilities are lacking, especially in the rural and suburban communities, are due to CNS infections. Incidentally, Human immunodeficiency virus infection (HIV) is increasing steadily in Africa, with the recent $\mathrm{WHO}$ report stating that '11.3 million cases out of 17 million worldwide are found in Africa with South Africa, Uganda, Kenya and Nigeria leading other African Countries' $^{\prime 38}$. It is now clear that HIV infection will be, or already is, a much greater problem in developing tropical countries. It may lead to epilepsy by direct invasion of the brain, as in HIV encephalopathy, or as a consequence of opportunistic infections, as in toxoplasmosis.

Although there is a high incidence of parasitic infections in Nigeria, there is little evidence that these parasites commonly cause epilepsy locally ${ }^{36}$. There are however, many reports from other parts of the world, especially other developing countries, incriminating parasites in the causation of epilepsy 39 . Cysticercosis is the commonest cause of epilepsy in some parts of the world due to the introduction of computed tomography (CT) in the 1970s and early 1980s which allowed for its detection. Epilepsy is the commonest presentation of neuro cysticercosis, frequently as an isolated clinical sign, to the extent that prevalence figures for idiopathic epilepsies in endemic regions cannot be accepted unless subjects have been examined with CT. This infection has been rarely reported in Nigeria unlike her neighbours, Cameroun and Togo, where cysticercosis was responsible for significant proportions of epilepsy cases $^{40,41}$. 
Echinococcosis and schistosomiasis may also parasitize the brain, but they rarely are a cause of epilepsy ${ }^{39}$. Cerebral schistosomiasis predominantly occurs in Asia and causes seizure as an acute meningoencephalitis or as chronic single or multiple granulomata. Hepatic schistosomiasis leading to portal hypertension presents as an encephalopathy that appears to occur early in infection, and may also present with seizures. The relationship between Trypanosoma Cruzi, the agent of Chaga's disease and epilepsy, is indirect, through cardiac embolization of the brain. In the African Trypanosoma infection, sleeping sickness, seizures may occur in the late stages and possibly also as sequelae in survivors ${ }^{39}$. Seizures are one of the hallmarks of the clinical presentation of cerebral malaria, due to Plasmodium falciparum. $P$. Vivax, the more common agent of malaria in Latin America, may be the commonest infection associated with febrile seizures in this region, although this is not proven ${ }^{39}$. Thirtyone percent of symptomatic epilepsies reported by Dada ${ }^{36}$ were due to CNS infections, cerebral abscess and malaria, while $22 \%$ of patients with temporal lobe epilepsy had febrile convulsions in childhood from malaria. Other parasitic infection that have been implicated include toxocariasis, ascariasis, filariasis and hydatid cyst ${ }^{36,39}$. In a publication by Danesi ${ }^{28}$ an incidence of $2.1 \%$ and $21.9 \%$ was reported for CNS infections and febrile convulsions respectively while $32.8 \%$ and $24.6 \%$ were documented in another series by Obembe and Ahmed ${ }^{21}$. These studies were carried out in the southern and northern parts of Nigeria respectively. Cerebrospinal meningitis is commoner in the north hence, the higher incidence in the latter study. Seizures are a common manifestation of cerebral tuberculosis, but not of tuberculous meningitis. Cerebrospinal fluid (CSF) studies and CT brain scans are the mainstay of diagnosis.

\section{Trauma}

Trauma and hypoxia are among the commonest causes of epilepsy in Nigeria. These factors may act alone or together in the perinatal period owing to poor obstetric care, or throughout life in acts of violence at home, work and in traffic accidents. Birth trauma can cause epilepsy following excessive moulding of the scalp and asphyxia with subsequent damaging effects on the hippocampus and amygdala resulting in incisural sclerosis. It accounts for $1-2 \%$ of symptomatic epilepsies in Africa ${ }^{2}$. In a large series of patients, it accounted for $3.4 \%{ }^{28}$.

Nigeria and the East African countries have the highest rate of automobile accidents per million-vehicle miles in the world and consequently post traumatic epilepsy is becoming increasingly common. The occurrence of seizure in the first week after head injury indicates a higher likelihood of another seizure. $20 \%$ will have a second seizure if the first seizure occurs between second and seventh week after head injury ${ }^{42}$. It accounts for between $8 \%$ and $12 \%$ of symptomatic epilepsies in Nigeria ${ }^{21,28}$.

\section{Tumours}

Cerebral tumours account for 3 - $10 \%$ of symptomatic epilepsies in Africa $^{2}$. With the introduction and installation of CT in some tertiary institutions in several African countries, more cases of epilepsy 
secondary to cerebral tumours are becoming obvious.

\section{Vascular}

Vascular lesions account for 6 $20 \%{ }^{2}$ in Africa but lower incidence rate of $3.3 \%{ }^{21}$ and $1.3 \%{ }^{28}$ were obtained among Nigerian PWE. Seizures occur in $15 \%$ of patients with cerebral infarction and become chronic in less than 5\%. Inflammatory vasculitis (e.g. polyarteritis nodosa, lupus erythematosus), subdural hematoma, arteriovenous malformation and intracerebral hemorrhage can present as seizures.

\section{Metabolic}

Metabolic derangements, such as pyridoxine deficiency which is associated with increased glutamic acid and reduced gamma aminobutyric acid (GABA) levels in the brain, may result in seizures. Other metabolic causes of epilepsy include aminoaciduria, hypoglycemia, hypocalcemia, hypomagnesemia, uraemia, alkalosis and water intoxication ${ }^{42}$. Insulinoma, causing hypoglycemia may rarely present with epilepsy ${ }^{43}$.

\section{Drugs}

Generalized seizures have
been reported in non-epileptic Nigerian subjects with normal EEGS after toxic doses of chloroquine ${ }^{39}$, more rarely with therapeutic doses ${ }^{44}$, and even during prophylactic treatment. Patients with epilepsy of low seizure threshold may be especially prone, which has prompted suggestions that the drug is contraindicated in such cases. The mechanism for these effects of antimalarial drugs is unclear, but chloroquine inhibits glutamate dehydrogenase activity. Mefloquine which has been associated with an increase in seizure frequency in epileptic patients reduces the half-life of valproate ${ }^{39}$.

\section{Seizure types}

The clinical manifestations of patients often depend on the seizure types. These clinical features are outlined under the subheadings of partial epilepsy and generalised epilepsy.

\section{Partial Epilepsy}

The clinical manifestations of partial seizures are determined by the cortical area involved. For example, seizures arising from the occipital region present with visual phenomena, those from the precentral gyrus with motor phenomena, and those from the postcentral gyrus with sensory symptoms. Seizures arising from the temporal lobe are usually associated with altered state of consciousness and therefore are complex partial seizures. Of the simple partial seizures, those with motor symptomatology remain the most common type. The seizures may involve only small groups of muscles, such as rhythmic twitching of a single finger or part of the tongue, or multiple muscle groups, such as clonic activity of the arm or leg. Rarely, there may be inhibition of tone, and rather than tonic or clonic movements, the patient becomes limp in one or two extremities. Versive seizures are characterized by forced turning of the head or eyes.

Simple partial seizures are less frequent than complex partial seizures in most series ${ }^{21,28,45}$ reported among Nigerian patients. Among 945 patients reviewed by Danesi ${ }^{28}$ partial seizures constitute the larger group with complex partial seizures accounting 
for 76.6 percent, and this observation was consistent with the series published by Osuntokun et al ${ }^{18}$ and Obembe et $\mathrm{al}^{21}$. This higher proportion of complex partial seizures is probably due to higher incidence of birth injuries, central nervous system infections and more importantly, recurrent childhood febrile convulsions ${ }^{28}$. Focal motor seizures may remain strictly localized or may spread to contiguous cortical areas, producing a sequential involvement of body parts, formerly known as a 'jacksonian march'. Following partial motor seizures, there may be paralysis of the muscle groups previously involved in the seizure. This weakness, termed Todd's paralysis, may last from minutes to hours and is helpful in determining the focus of the seizures.

Two syndromes in which partial motor seizures are major component are, namely; (a) Benign rolandic epilepsy, which occurs in childhood and characterized with partial motor seizures, with or without secondary generalization, and associated with central and mid temporal spikes. It is frequently familial and has excellent prognosis, and (b) a syndrome described by Aicardi and Chevrie ${ }^{46}$ which occurs in children between 2 and 6 years of age and characterized with simple partial seizures which occur in association with atypical absences and myoclonic - atonic seizures. EEG commonly demonstrates focal abnormalities during the wakeful state and an almost continuous, diffuse slow spike - and - wave pattern during sleep. The prognosis for remission of the seizures is favorable.

Automatic behavior or psychomotor symptoms occur frequently in complex partial seizures (CPS). It consists of involuntary motor activities occurring when consciousness is impaired during either the ictal or the postictal period. Some patients with CPS and their parents are aware of an impending seizure days or hours before the event. This seizure prodrome may consist of headaches, irritability, insomnia, changes in personality or activity level, or a feeling of impending doom. Prodromes preceding CPS are not as common as before generalized tonic-clonic seizures. The prodrome is not an ictal event and must be differentiated from an aura, which is an ictal phenomenon. The physiological basis of the prodrome has not been established.

Aura is the portion of the
seizure that occurs before consciousness is lost and for which memory is retained. It varies from patient to patient, and includes somatosensory, auditory, visual, olfactory and gustatory symptoms; visceral sensations and complex subjective experiences. It may be very helpful in warning the patient that impairment of consciousness is imminent. It occurs in 50 to 83 percent of patients with CPS.

The automatic behaviour of CPS may be the continuation of an activity that was in progress prior to the seizure (perseverative automatism) or may be new activity (de novo automatism). De novo automatism are further divided into reactive, in which the patient responds to external or internal environmental stimuli, and released, in which the patient carries out actions that are usually inhibited socially. Motor activities during automatisms are usually fragmentary, and rarely do well coordinated movements occur. 
Types of automatisms that have been described include, alimentary, gestural, sexual automatisms, mimicry, ambulatory and verbal, ninety-five percent of adult patients with CPS would have automatisms.

Holmes divided CPS into 3 types based on clinical manifestations and EEG features. In Type 1 CPS, the impairment of consciousness begins with a motionless stare and then is usually followed by automatic behaviour, while in Type II seizures the impairment of consciousness occurs at the same time as automatisms. Type III seizures are characterized by loss of body tone (drop attacks) followed by confusion, automatic behaviour, amnesia and gradual recomposure. Type I accounts for 40.6 percent while Type II, 50.7 percent and Type III, 8.7 percent of CPS cases in children ${ }^{47}$.

It is worth-noting that when seizures arise from the dominant hemisphere speech arrest is common, whereas involvement of the nondominant hemisphere may also result in speech arrest, but there may be perseveration of speech with continuous repeating of words or phrases. Autonomic symptoms may occur with both simple and complex partial seizures. Abdominal pain and vomiting usually occur in complex partial seizures. Somatosensory or special sensory symptoms occur with involvement of the cortical areas subserving sensory functions. Painful partial seizures are rare but have been well described ${ }^{47}$. A headache rarely may be the sole ictal manifestation of both simple partial and complex partial seizure ${ }^{47}$. Psychic symptoms are usually components of complex partial seizures.

\section{Generalized Epilepsy}

Generalized tonic - clonic (GTC) seizures constitute the largest subgroup of generalized epilepsies in Nigerian children ${ }^{21,45}$. It accounted for between 25 and 65 percent of the generalized epilepsies in several series published in Nigeria ${ }^{28,45}$. Though, community based studies showed a higher prevalence of partial seizures over generalized, the latter is more prevalent in hospital admissions data $^{2}$. There are two basic types; primary GTC seizures with bilaterally symmetrical involvement without focal features at onset, and secondary GTC seizures which begin focally and then become generalized. The latter accounted for 54.6 percent of generalized epilepsy in a Nigerian population ${ }^{7}$. Aura is common to the latter and the presence of aura is strongly indicative of a focal onset.

GTC seizures may also occur in the reflex epilepsies. Reflex epilepsy describes a condition in which seizures are precipitated by clearly recognized stimuli. In reflex epilepsies, the seizures are either primary; in which seizures occur only following a specific stimulus, or secondary; in which there is an underlying seizure disorder and the seizure occurs at times other than as reflex phenomena. Reflex seizure is rare, occurring in approximately 5 per cent of patients with seizures ${ }^{48}$.

Photo sensitive epilepsy, a form of reflex epilepsy, is a photoconvulsive response to photic stimulation. It is frequently but not always associated with clinical seizures. The seizures, if present, are primarily generalized. It is present in 40 percent of patients with absence seizures and 20 percent of patients 
with GTC seizures. It is however rare in patients with partial seizures. Jeavons classified photosensitive epilepsy into two categories, namely; (i) pure photosensitive epilepsy, in which clinical seizures occur only when patient is exposed to a flickering light source and (ii) epilepsy with photosensitivity in which spontaneous seizures as well as those induced by flickering light occur ${ }^{49}$. Photosensitive epilepsy usually appears around puberty with a higher incidence among females (F/M 1.7:1). The occurrence of photoparoxysmal discharges to photic stimulation on EEG recordings tends to have a seasonal variation with lower incidence in summer, probably reflecting lower cerebral neuronal excitability and consequent less frequent discharges in summer than in winter ${ }^{50}$. The major precipitant of seizures is the television ${ }^{49}$. Photo sensitive epilepsy should be distinguished from self induced epilepsy.

Primary reading epilepsy was first described by Bickford et al in $1957^{51}$. Patient characteristically experiences myoclonic jerking of the jaw while reading. If the patient continues reading, a GTC seizure ensues. Initially, the patient has a feeling of jaw movement without actual movement then develops actual jerks before the tonic - clonic seizures. This process ceases when reading is discontinued. EEG is normal inter-ictally. Secondary reading epilepsy is less stereotyped in pattern. It may occur spontaneously or may be precipitated. Jaw jerking phenomenon is absent and EEG recording is abnormal even when patient is not reading.
In absence (Petit Mal) seizures, the hallmark is suppression of mental functions, usually to the point of complete abolition of awareness, responsiveness and memory. It starts abruptly without an aura, and lasts from a few seconds to half a minute but occasionally may last for over a minute. On going activity is interrupted, the patient changes facial expression and becomes transfixed (like a statue). Patient stares with a motionless distant expression. At the end of a seizure, the patient frequently returns to the gesture, sentence or other interrupted activity. Postictal fatigue does not occur although there may be momentary confusion owing to the 'time loss'. This 'time loss' may serve as a cue that a seizure occurred, even though there may be complete amnesia for ictal events. Absence seizures are rare among Nigerian epileptic patients, with an incidence of between 3 and 10 percent $^{20,21}$, though Danesi reported an incidence of 11.2 percent $^{28}$ in a series. This variation may not be unrelated to patients' selection criteria and availability of facilities to facilitate seizure classification.

Myoclonic seizures are brief, unexpected muscular contractions which are usually bilateral but asymetrical, occasionally unilateral. There is no disturbance of consciousness. It occurs on awakening or first hour after getting up in the morning. Sometimes it may be intense, throwing the patient to the ground. The primary epileptic myoclonus include; (i) Primary generalized epileptic myoclonus, (ii) Infantile spasms, (iii) Juvenile myoclonic epilepsy of Janz, (iv) Epilepsia 
partialis continua and (v) As component of other seizure types.

The Lennox - Gaustaut syndrome, a form of secondarily generalized epilepsy, is a mixture of seizure types frequently comprising tonic, tonic-clonic, atypical absences, head drops (which represent a form of atonic seizures) or myoclonic seizures. It constituted 2.4 percent of all generalised epilepsies in Nigeria ${ }^{28}$.

The clinical manifestations of infantile spasm vary considerably. Some are characterized by brief head nods, while others consist of violent flexion of the trunk, arms and legs. The diagnosis may often be delayed, since parents and even the physician may not recognize spasms as seizures. The onset is usually in the first 2 years of life with peak age of onset between 4 and 6 months. The attacks may be as frequent as 50 100 per day. It is frequently associated with mental retardation, and this is present in 90 percent of cases with EEG hypsarrythmia ${ }^{47}$.

Febrile seizures occur between 6 months and 5 years of age. Although there are some exceptions, children outside this age range are less likely to have febrile seizures ${ }^{47}$. The prevalence is higher in blacks than in whites, and incidence is higher in boys than girls. The seizures may be of any type, although they are usually generalised tonic - clonic. By definition, fever precedes the onset of the seizures. The seizures usually occur early in the course of the febrile illness, and in some children the first indication to the parents of an illness is the seizure. Most studies agreed that children who have had one or more febrile seizures are at increased risk for the development of epilepsy.
The risk of developing epilepsy following febrile seizures has been reported to vary from 2 to 57 percent. The variable findings result from the different methods used to select the patients with febrile seizures, varying definitions of febrile seizures and epilepsy, and the duration of follow-up of the populations. It has been documented that febrile seizures might predispose to complex partial seizures, especially when the seizures are recurrent, atypical (i.e. focal in origin, documented postictal paralysis or seizures lasting longer than 10 minutes) and when a family history of febrile seizures is present.

\section{Investigations}

Despite the fact that the diagnosis of epilepsy is largely based on clinical data, the evaluation of patients with suspected seizures requires the use of investigative modalities such as electroencephalography and neuroimaging facilities.

\section{Electroencephalography}

Electroencephalography (EEG) has played a crucial role in the formulation of our present concept of epilepsy. Epilepsy is sometimes regarded as a test case for assessing the clinical value of EEG as it is a disorder of cerebral function and EEG is a functional investigation. It can supply supportive evidence for the diagnosis of epilepsy and also provide critical clues to the classification of epileptic seizures and syndromes. In addition, it may help in anatomical localization of an underlying cerebral pathology, but neuroimaging techniques provide more useful information concerning structural abnormalities. EEG indirectly aids in the selection of appropriate antiepileptic drugs and, in 
certain circumstances, also helps in formulating a prognosis, since it is extremely valuable in the determination of seizure type.

Most routine EEGs in epileptic patients are obtained in the interictal state and the diagnostically useful finding is the epileptiform patterns (EPs) which suggests the presence of real epileptogenic process, although not pathognomonic of epilepsy. Electro-encephalographic recordings do not consistently reveal epileptiform patterns. Only 30 to 50 percent of patients with probable epilepsy would have epileptiform patterns on the first EEG. If multiple recordings are obtained, however, that proportion increases to 92 percent $^{52}$. Interictal EEG records of Nigerian patients with epilepsy compared with their British counterparts revealed that interictal abnormalities were less common in Nigerian (15.7 \%) than in British $(52.9 \%)$ patients ${ }^{53}$. This was attributed to the larger amount of sunshine present in the tropics.

Out of 626 epileptic patients studied for presence of EP on EEG in Ibadan, only 46 percent showed these patterns and the proximity of seizures to EEG examination, the age of onset of seizures and duration of epilepsy were significantly correlated to the occurrence of the EPs ${ }^{54}$. In an earlier study, by Osuntokun et al ${ }^{55}$ in Ibadan, little or no correlation was found between the clinical types of epilepsy and the EEGs findings, although more than 70 percent of 560 patients studied demonstrated abnormalities on the EEG recordings. Ahmed et al ${ }^{45}$ reported normal EEG recordings in 35.6 percent of 351 patients in Kaduna while Danesi ${ }^{28}$ recorded lack of normal findings in all 945 patients studied in Lagos.

In specialized epilepsy centres, depth electrodes, nasopharyngeal and sphenoidal electrodes, are now being used to facilitate the demonstration of $\mathrm{EPs}^{52}$, due to temporal lobe abnormalities. In patients with unclassifiable seizures, video recording of attacks with simultaneous EEG recordings are employed to facilitate direct observation of seizures.

\section{Neuro-imaging \\ Computerized Tomography}

With the introduction of the computerized tomography (CT) in the 1970s, the practice of neuroradiology and clinical neurology has been transformed. It is very useful in the detection of structural lesions and the determination of the exact location of such lesions. It is also used in the determination of cerebral atrophy, which is the commonest abnormality demonstrated in epileptic patients ${ }^{56}$. The importance of CT was established at the 21st European Congress of Electroencephalography and Epilepsy in 1975, where CT features in 1702 selected patients were presented with 45 percent exhibiting cerebral atrophy 57 . The proportion of abnormalities on CT is higher in late onset epilepsy as localization - related epileptic syndromes are commoner in the adult population ${ }^{56,58}$. A descriptive study of 103 consecutive children with epilepsy for over 5 year period showed abnormal films in 51.5\% with most patients having hydrocephalus followed by cerebral atrophy and infarct. A high incidence of abnormal findings was reported in those with partial seizures ${ }^{59}$. The CT findings in 75 adult Nigerian patients reported by 
Ogunniyi et al ${ }^{60}$ showed normal findings in 54.7 percent, cerebral atrophy in $21.3 \%$ while cerebral tumours, vascular lesions and porencephaly accounted for the remaining.

\section{Plain Radiology}

Plain skull X-ray still has a definite place $^{57}$ in developing countries although the development of advanced imaging techniques has made it almost irrelevant. It is still cheap, widely available and relatively innocuous despite its inferiority in both sensitivity and specificity to newer techniques. It is useful in the detection of bony changes (as seen in raised intracranial pressure and some tumours) and abnormal calcification (commonly associated with cerebral tumours, arteriovenous malformations and infections like cysticercosis, toxoplasmosis and cytomegalovirus).

\section{Positron Emission Tomography (PET)}

This technique has, at present, few applications in the evaluation of epileptic patients. In interictal studies of patients with complex partial seizures, focal glucose hypometabolism in the abnormal temporal lobe is a relatively consistent finding. There is also correlation between degree of cell loss on pathologic examination of the surgically removed temporal lobe and the degree of hypometabolism. It is usually indicated in patients considered for temporal lobectomy in some centres. Using ${ }^{18}$ Fluorine-labelled glucose studies, increased diffuse utilization has been demonstrated in absence seizures.

\section{Single Photon Emission Computerized Tomography (SPECT)}

This is also not commonly used in the evaluation of epilepsy. It is both a structural and functional neuroradiological investigation as it reveals the presence of structural lesions and disturbances in metabolism. It utilises radioisotope scanning to delineate cerebral perfusion and structural abnormalities.

\section{Magnetic Resonance Imaging (MRI)}

This technique is superior to CT in the detection of most structural lesions, including tumours, and especially in the evaluation of demyelinating diseases, lesions in the posterior fossa and many white matter disorders. It is not easily available in many developing countries. MR spectroscopy is however superior to $\mathrm{MRI}$ in delineating the cellular damage in demyelinating diseases. In patients suffering from intractable temporal lobe epilepsy, in whom pre-surgical localization of the epileptic focus is one of main problems, studying the seizure pattern and EEG findings complemented by MRI results and neuropsychological assessment have proved inadequate. MR spectroscopy has proved superior in pre-surgical localization. MR spectroscopy has been used to detect N - acetyl aspartate reduction in the affected temporal lobe and this positively correlates with clinical EEG and structural lateralization.

Other neuroradiological investigations are employed less frequently as a result of the introduction of CT and MRI scanning. The older methods of injecting air either into the cerebral spinal fluid via a lumbar puncture (air encephalogram) or directly into the ventricle via a needle inserted through 
a burr hole in the skull (air ventriculogram) has been superceded by CT scanning. Cerebral angiography retains an important place in the investigation of intracranial tumours and vascular lesions. Radio-isotope brain scan is no longer commonly used, due to high false negative rates, in the detection of brain tumours.

Biomagnetic imaging, however, using biomagnetometer provides information about the body's electrical activity, and is entirely non-invasive and can map the sources of electrical activity in three dimensions with resolution. It is of potential in the diagnosis of epilepsy. Most of these facilities especially the functional imaging techniques are not available in Nigeria. The investigations of PWE in Nigeria are limited to CT brain scans and MRI.

\section{Treatment}

Epilepsy is a neurological disease, which is primarily diagnosed medically and as a rule treated by pharmaco-therapy except in cases of refractory epilepsy that may sometimes require surgical intervention. Treatment with an antiepileptic drug is usually begun when the patient has had more than one unprovoked seizure within a year, whatever the type. Most patients with recurrent epileptic seizures require treatment. The question of whether to treat a single seizure is controversial $^{61}$. The single attack of seizure may be provoked and there are cases when episodes are separated by years. It is however important to note that patients who have had unprovoked seizure have a substantial chance of recurrent events i.e. epilepsy, with the frequency ranging from 31 to 71 percent depending on other risk factors ${ }^{61,62}$. It is advised that patients with an underlying neurologic abnormality or cerebral lesion or a specific syndrome such as juvenile myoclonic epilepsy should be treated ${ }^{62}$.

\section{Drug Therapy}

The diagnosis of epilepsy has profound implication to the sufferer, not least of which is the fact that medication may have to be taken every day for many years. The drugs may cause toxic side effects, require continual medical supervision and may have complex psychosocial consequences. Therefore the decision to initiate drug treatment requires that the diagnosis of epilepsy must be certain, and estimates of the chances of seizure recurrence must be made and the extent to which anticonvulsant therapy will improve these chances be considered. This decision about treatment should be made after an extensive discussion with the patient about the cost, the risk and benefits of treatment and the risk associated with no therapy. The best drug for the particular type of seizure is selected and administered in a dose high enough to bring the plasma drug concentration into a therapeutic range without unacceptable side effects. The goal should be restoration of a normal life through complete control of seizure with the use of a single drug that has no side effects.

Drug compliance must be emphasized. Among 345 adult Nigerians with epilepsy, only $25.5 \%$ complied with therapy while 107 patients defaulted. It is not unusual to find patients with epilepsy seeking alternative treatment methods in Nigeria ${ }^{22}$, and this probably explain late presentation in the hospital, high default rate and frequent presentations 
with status epilepticus in the emergency rooms. The study by Danesi and Adetunji ${ }^{63}$ reported a $47.6 \%$ usage of African traditional medicine and $24.1 \%$ combined usage of traditional and spiritual methods. These groups of patients used these methods for 1 5 years before seeking help in the hospitals.

Carbamazepine, Phenytoin, valproic acid, phenobarbital and primidone are all effective in reducing the frequency of partial seizures. There are, however, conflicting data on whether carbamazepine is more effective than valproic $\operatorname{acid}^{64,65}$. Notwithstanding, Carbamazepine and Phenytoin are the drugs of choice for partial seizures. For patients with tonic clonic seizures, valproic acid, phenytoin and carbamazepine are all effective.

Valproic acid is the drug of choice for patients with tonic - clonic seizure, and spike - wave discharge on the electroencephalogram and for patients with other forms of generalized epilepsy, particularly myoclonic jerks and absence seizures. Ethosuximide is also a useful drug for absence seizures. For patients who have both absence seizure, and tonic-clonic seizures or myoclonic jerks, valproic acid is preferable.

Carbamazepine was strongly recommended by Familusi ${ }^{66}$ in the management of seizure disorders, especially intractable seizures, in Nigeria despite its high cost and limited availability a decade ago. It has however gained wide acceptance due to its favourable anticonvulsant efficacy and supplementary psychotropic use. Treatment with carbamazepine should be initiated at low doses (200 to $400 \mathrm{mg}$ daily) to allow development of tolerance. The dose can then be increased by increments of $200 \mathrm{mg}$ per day at intervals of two to four weeks until a maintenance dose has been reached that controls the seizure disorder completely. The final dose often depends on the extent to which carbamazepine induces its own metabolism.

In some patients, high peak plasma concentrations can result in intermittent central nervous system side effects about two hours following administration of the drug three or four times daily. This problem can be overcome by prescribing a controlled release formulation which can be given once or twice daily, although this is fairly expensive but readily available in Nigeria.

In addition to inducing its own metabolism, carbamazepine can accelerate the hepatic oxidation and conjugation of other lipid - soluble drugs. The most common interaction is with oral contraceptive pills and most women require an increase in the daily dose of oestrogen from 35 to $50 u g$ or more. It also accelerates the metabolism of valproic acid, ethosuximide, corticosteroids, anticoagulant and antipsychotic drugs, and paradoxically, whereas phenytoin induces the metabolism of carbamazepine, carbamazepine inhibits the metabolism of phenytoin. Thus adding phenytoin decreases plasma carbamazepine concentration by about a third, whereas adding carbamazepine increases plasma phenytoin concentration by a similar amount. Drugs like cimetidine, erythromycin, isoniazid verapamil, propoxyphene and dilitiazem inhibit metabolism of carbamazepine sufficiently to cause toxic effects. 
Phenytoin is effective for the treatment of partial and tonic - clonic seizures. It appears to act by inducing voltage dependent blockade of sodium channels. A starting dose of $5 \mathrm{mg}$ per kilogram of body weight raises plasma concentrations within the target range of 10 to 20ug per milliliter in most patients, but some will have higher concentrations and neurotoxic effects. Some patients require a higher dose, for example, those who abuse alcohol and have increased hepatic microsomal enzyme activity. The dose can be increased, in general, by $100 \mathrm{mg}$ if the plasma concentration is $5 \mathrm{ug}$ per milliliter or less, but no more than 50mg should be added if the plasma drug concentration is higher. Some patients can benefit from plasma concentrations above 25ug per milliliter without adverse effects.

Phenytoin can induce the oxidative metabolism of many lipid soluble drugs including carbamazepine, valproic acid, ethosuximide, anticoagulant agents, corticosteroid and cylosporine. Drugs like allopurinol, amiodarone, cimetidine, imipramine and some sulfonamides, inhibit the metabolism of phenytoin.

Phenobarbitone is as effective as phenytoin and carbamazepine in abolishing partial and generalised tonic - clonic seizures. The drug, at the cellular level, prolongs inhibitory postsynaptic potentials by increasing the mean chloride - channel opening time and hence the duration of gamma - aminobutyric acid - induced bursts of neuronal activity. This drug has been successfully used to treat epilepsy by primary health workers in rural Africa and this is likely to continue. Good seizure control was reported in $52.9 \%$ of children with epilepsy by Sykes ${ }^{67}$ in Benin City, Nigeria but the response to medication was less satisfactory for children under one year. In a study that assessed the effectiveness of anticonvulsant therapy among 175 Nigerian patients with epilepsy, phenobarbital was the single most commonly prescribed agent due to economic considerations, availability and favourable seizure control ${ }^{68}$. Furthermore, the WHO recommended phenobarbital as the drug of choice in the management of seizures in developing countries ${ }^{39}$.

To minimize the sedative effect the starting dose should be low i.e. $60 \mathrm{mg}$ in adults and $4 \mathrm{mg}$ per kilogram of body weight in children, and increased gradually according to the response. The value of measuring plasma phenobarbital concentration is limited, because the concentration associated with optimal control varies considerably ${ }^{61}$. In addition, the development of tolerance to the drug's central nervous system side effects makes the toxic threshold imprecise. The main limitation of phenobarbital is its propensity to alter $\operatorname{cognition}^{69}$, mood and behaviour. It can cause fatigue and listlessness in adults. Memory, mood and learning capacity may be subtly impaired ${ }^{69}$. Depression, arthritic changes and Duputyren's contracture can be associated problems. Tolerance to the deleterious cognitive effects of phenobarbital can develop, but unfortunately, tolerance to its anticonvulsant effect can also develop. Phenobarbital is the archetypal enzyme inducer and can accelerate the metabolism of many lipid - soluble drugs. 
Primidone is metabolized to phenobarbital and another active metabolite, phenylethylmalonamide. The efficacy of primidone is similar to that of phenobarbital, but primidone is less well tolerated ${ }^{64}$.

The anticonvulsant properties of valproic acid were first reported in 1961 , but it is only in the past 15 years that the drug has attracted wide interest. It is effective in patients with idiopathic generalized epilepsy. The drug acts by limiting sustained repetitive neuronal firing through voltage - and use - dependent blockade of sodium channels, although it is also likely to have other effects. The starting dose for adults and adolescent is $500 \mathrm{mg}$ once or twice daily, with subsequent increases according to the response. Because valproic acid can take several weeks to become fully effective, the dose should not be increased sooner. Routine plasma concentration monitoring is not helpful as there is no clear-cut relation among the plasma concentration, its effect and toxicity, and since the daily variation in plasma concentration is wide.

Common side effects are doserelated tremor, weight gain due to appetite stimulation, thinning or loss of hair (usually temporary) and menstrual irregularities including amenorrhea. Approximately 20 percent of all patients receiving the drug have hyperammonemia without hepatic damage. This effect is usually asymptomatic but occasionally can cause confusion, nausea and vomiting $^{61}$. Valproic acid inhibits several hepatic metabolic processes including oxidation, conjugation and epoxidation. Aspirin displaces valproic acid from its binding sites on plasma proteins and inhibits its metabolism. Valproic acid does not interfere with the action of oral contraceptives.

The first reports of clonazepam use in epilepsy were made in 1970 and since then there have been a number of clinical studies. Clonazepam is effective in preventing absence seizures, myoclonic jerks and tonic - clonic seizures. It is also very useful in the treatment of status epilepticus. As with other benzodiazepines, however, the sedative effect and the development of tolerance substantially reduces its usefulness. Few patients have good responses, and in nearly 50 per cent of patients, the epilepsy is exarcebated when the drug is withdrawn ${ }^{70}$. The therapeutic role of clonazepam is therefore limited, and it is used mostly for refractory myoclonic seizures.

Ethosuximide is highly effective against petit mal (typical absence) seizures. It acts by reducing low threshold, transient, voltage dependent calcium conductance in thalamic neurons. In children older than six years, 500mg daily is a reasonable starting dose, with further increments as necessary to a maximum of 1 to $2 \mathrm{gm}$ daily. For most patients the dose can be increased every two to four weeks, but more rapid titration may be needed.

The side effects of ethosuximide usually involve the gastro intestinal tract (nausea, vomiting and abdominal pain) or central nervous system (lethargy, dizzines and ataxia). These problems are often not correlated with high plasma concentration of the drug. The metabolism of ethosuximide is altered by enzyme inducers such as phenytoin and carbamazepine and by 
enzyme inhibitors such as valproic acid.

\section{Treating Refractory Seizures}

In about 30 percent of patients with epilepsy, the seizures are refractory to treatment with a single antiepileptic drug ${ }^{71}$. Many of these patients have partial seizures due to an underlying anatomical lesion, and the addition of other drugs is successful only about 10 percent of the time ${ }^{61,71}$. Before long-term treatment with more than one drug is undertaken, all reasonable options for monotherapy should be exhausted. The diagnosis of epilepsy should be reassessed in all patients with resistant seizures before assuming the seizures to be intractable. Even in specialist epilepsy clinics, the seizures in up to 20 percent of such patients may prove to be non-epileptic in origin. Also, the cause of the epilepsy should again be considered, and progressive cerebral disease excluded.

Furthermore, a complete treatment history should be taken as in most chronic cases the previous response to an individual drug is a useful guide to any future response. Information should be obtained regarding the drugs previously taken, the duration of therapy, the maximum dosage and serum levels, and compliance. If one drug is ineffective, an alternative drug should be introduced gradually. If the patient has a response to the second drug, an attempt should be made to withdraw the original drug. Only if this attempt is unsuccessful, should two-drug therapy be continued. No controlled clinical trials have identified the best second drug or combination of drugs ${ }^{61}$.
For patients with partial or tonic-clonic seizures, most specialists used two of the three first-line drugs - namely, carbamazepine, valproic acid or phenytoin, for combination therapy although their mechanisms of action overlap. Patients with myoclonic seizures who do not have a response to valproic acid, clonazepam may be added, whereas patients with intractable typical or atypical absence seizure may have a response to valproic acid combined with ethosuximide. Many patients receive treatment with three or more antieplieptic drugs when their seizures are intractable, although few are made free of seizures by this approach. The likelihood of toxic effects, especially cognitive dysfunction, increases with the number of epileptic drugs prescribed ${ }^{61}$. Also it may be counter productive to introduce a sedative drug such as phenobarbital or primidone, because if the drug is ineffective, its subsequent withdrawal will probably decrease the control of seizure.

The addition of one of the newer drugs - lamotrigine, gabapentin, vigabatrin, clobazam, oxcarbazepine or felbamate - may be more appropriate. Studies of vigabatrin (gamma-vinyl GABA), a GABA analogue, have reported that 33 $62 \%$ of patients with intractable epilepsy experience a greater than $50 \%$ reduction in seizures; patients with partial epilepsy have the highest success rates 72,73 , when given vigabatrin at doses of $2-3 \mathrm{~g} /$ day. Other GABA agonists that are undergoing clinical trials include stiripentol and progabide. Zonisamide, a sulphonamide drug, and the imidazole derivatives - denzimol and 
nafimidone are also being tried. A cinnarizine derivative, fluzarine, and several new barbiturate drugs such as cinromide, ralitoline, mexiletine and fluzinamide, are also being investigated in the treatment of refractory seizures ${ }^{74}$.

Other miscellaneous antieplieptic medication in use, though rarely, include Beclamide (a propionamide derivative introduced in 1953) reported to be efficacious in grand mal and complex partial epilepsy; paraldehyde (a polymer of acetaldehyde which is poorly water soluble) used since 1882 as intramuscular emergency treatment for acute epilepsy and intravenously for status epilepticus; and corticosteroid drugs, especially Adrenocorticotrophic hormone $(A C T H)$, occasionally used in epilepsy, especially in infantile spasms with often an immediate response.

\section{Withdrawing medication}

In more than 60 percent of patients who remain free of seizures, the medication can eventually be withdrawn successfully ${ }^{75}$. Some physicians wait for two years, and others for five. Most advise a slow reduction in the dose of each drug during a period of two to six months. Children who have benign epilepsy with rolandic spikes or benign familial neonatal convulsions usually do well after drug withdrawal whereas those with juvenile myoclonic epilepsy often have relapses.

Patients with idiopathic generalized seizures, whether absence or tonic clonic seizures are least likely to have a recurrence after control has been achieved and medication withdrawn. Even complex partial seizures can disappear, after a long period of control. The patients with the highest probability of remaining free of seizures after the medication has been discontinued are those who have had no seizures for a long period, those who had few seizures before control was achieved and those with a normal neurological examination and no structural brain lesion.

\section{Surgical Management}

Patients who continue to have seizures despite good drug compliance may sooner require the surgical option. Such patients should be referred to an epilepsy center for several reasons. First, the more seizures a patient has, the more difficult it is to control the epilepsy, that seizures may beget seizures has been hypothesized for more than a century ${ }^{12}$. Second, it may be hard to classify the seizures on the basis of accounts given by untrained eyewitnesses making video electroencephalographic monitoring useful in arriving at a definitive diagnosis and classification. In some patients, apparently uncontrolled seizures are really pseudo-seizures which video EEG monitors will show and such patients are better treated with psychotherapy. Third, patients with uncontrolled seizures often receive multiple drugs, which may have substantial toxic effects that can be reduced by simplification of the regimen. Fourth, in patients who have not had adequate responses to the standard drugs, there may be an opportunity to try an experimental drug. Finally, appropriate decisions about surgical treatment are best made at a specialized center.

The surgical therapy for epilepsy has focused mainly on 
temporal lobectomy. The excision of the anterior temporal lobe in one block as practised by the Maudsley group has been improved upon by the Zurich group who practised microsurgical, selective amygdalo hippocampectomy. Various centres reported a 60 - $80 \%$ success rate with cessation of seizures in about $50 \%$ and very significant reduction in frequency in about $30 \%{ }^{76}$.

Division of the corpus callosum

was occasionally performed to prevent spread of seizure discharges from one hemisphere to the other 77 however the Yale group reported that some patients experience more intensive focal seizures after the procedure ${ }^{78}$. Stimulation of the cerebellum has been reported to suppress seizures ${ }^{79}$, but this has not gained acceptance in clinical circles. There are no published data on epilepsy surgery in Nigerians and epilepsy surgery is non-existent in $98 \%$ of African countries ${ }^{80}$. This is an area of challenges for neurosurgical practice in our country where epilepsy is common.

\section{Dietary Management}

Ketogenic diets have been occasionally used in the management of intractable epilepsy since Wilder's original report in $1921^{81}$. The classical diet is based on an estimated daily requirement of 75 kilocalories per body weight; $50 \%$ of calories are given as fat, the remainder as protein and carbohydrates. The fats are mainly long chain fats such as butter and cream. Medium chain triglycerides (MCT), largely octanoic and decanoic acids, have been used in some centers. In a study from Oxford ${ }^{82}, 41 \%$ of 57 children with epilepsy showed a greater than $90 \%$ reduction in seizure frequency within one month of starting the diet. $81 \%$ of the children had a greater than $50 \%$ reduction in seizure frequency, and only $19 \%$ showed no benefit. There is no report of this therapeutic option among Nigerian patients.

\section{Quality of life among patients with epilepsy \\ Quality of life among patients} with chronic epilepsy has been little study among Nigerians. Main aspect of life events affected from a study done in Ibadan ${ }^{83}$ was feeling of energy deficits. This was closely followed by memory, fear of experiencing the next seizure and work and social limitations. Cognitive impairments due either to the recurrent seizures ${ }^{84,85}$ or the antiepileptic drugs contribute to disruption of life quality 69, 71, The social problems encountered by schoolchildren with epilepsy as a result of negative attitudes and beliefs are enormous. The school teachers' perception plays a significant role in the approach to care of the affected students. A study ${ }^{86}$ demonstrated that despite the fairly high level of education among the teachers in Nigeria the mean overall score for correct response for knowledge on epilepsy was $52.9 \%$, and majority of these teachers had negative attitudes and beliefs.

There is an urgent need for public awareness and education with the objective of eradicating the stigma attached to epilepsy and getting the community and primary health care workers actively involved in the management of affected persons. 


\section{REFERENCES}

1. Senanayake, $\mathrm{N}$ and Roman, G.C.: Epidemiology of epilepsy in developing countries. Bull. World Health Organisation, 1993; 71(2): 247-58.

2. Osuntokun, B.O.: Epilepsy in Africa. Trop. Geogr. Med., 1978; 31: 24-31.

3. Reynolds, E.H.: Historical aspects. In 'Epilepsy, Behaviour and Cognitive Function', 1988; John Wiley Medical Publication. pp 3-8. (Trimble, M.R and Reynolds E.W. ed).

4. Saint Mark Gospel, Chapter 9, verses 17-27. The Holy Bible. King James Version.

5. Hughes J.R. Dictator Perpetuus: Julius Caesar - did he have seizures? If so, what was the etiology? Epilepsy Behav. 2004; 5(5): 756-764.

6. Giel, R.: The epileptic outcast. East Africa Med. J., 1968; 45: 27-31.

7. Dada, T.O. and Odeku, E.L.: Epilepsy in the Nigerian patient. A review of 234 cases W. Afr. Med. J. 1966; 15: 15363.

8. Awaritefe, A., Longe, A.C., Awaritefe, M.: Epilepsy and Psychosis: A comparison of societal attitudes. Epilepsia, 1985; 26(1): 1-9.

9. Osuntokun, B.O. and Odeku, E.L.: Epilepsy in Ibadan, Nigeria: a study of 522 cases. Afr. J Med. Sci., 1970; 1: 185200.

10. Osuntokun, B.O.: Epilepsy in the developing countries: The Nigerian profile. Epilepsia, 1972; 13 : 107-11.
11. Jackson, J.N.: On the anatomical, physiological and pathological investigation of epilepsies. Reports of the West Riding Lunatic Asylum, 1873; 3: 315-39.

12. Gowers, W.R.: Epilepsy and other chronic Convulsive Diseases: their causes, symptoms and treatment, 1881; Churchill, London.

13. Trimble, M.R.: Anticonvulsant Drugs and Cognitive function: A review of the literature. Epilepsia, 1987; 28 (suppl.3): 537-545.

14. Gaustaut, H. Dictionary of Epilepsy I. Definitions. World Health Organisation, Geneva, 1973 pp 75.

15. Shovon, S.D.: Epidemiology, classification, natural history and genetics of epilepsy. Lancet, 1990; 336: 93-6.

16. Hauser, W.A., Annegers, J.F., Kurland, L.T.: Prevalence of epilepsy in Rochester, Minnesota: $1940 \quad-1980$. Epilepsia, 1991; 32: 429-45.

17. Dada, T.O.: Epilepsy in Lagos, Nigeria. Afr. J. Med. Sci., 1970; 1: 161-84.

18. Osuntokun, B.O., Adeuja, A.O., Nottidge, V.A.., et al: Prevalence of epilepsy in Nigerian Africans: a community-based study. Epilepsia, 1987; 28(3): 272-9.

19. Longe, A.C. and Osuntokun, B.O.: Prevalence of neurological disorders in Udo, a rural community in Southern Nigeria. Trop. Geog. Med., 1989; 41(1): 36-40. 
20. Osuntokun, B.O., Bademosi, O., Familusi, J.B. et al: Electroencephalographic correlates of epilepsy in Nigerian children. Dev. Med. and Child Neurology, 1974; 16(5): 659-63.

21. Obembe, A. and Ahmed, M.H.: Epilepsy in Kaduna: A study of 164 Youths. Nig. Med. Pract., 1988: 16(2); 45-8.

22. Ogunniyi, A., Oluwole, O.S., Osuntokun B.O.: Two-year remission in Nigerian epileptics. East Afr Med J. 1998; 75(7): 392-5.

23. Danesi, M.A., Odusote, K.A., Roberts, O.O. et al. Social problems of Adolescent and Adult epileptics in a Developing country, as seen in Lagos, Nigeria. Epilepsia, 1981; 22: 689-96.

24. Shamansky, S.L. and Glaser, G.H.: Socioeconomic characteristics of seizure disorders. Epilepsia, 1979; 20: 457-74.

25. Watts, A.E.: The natural history of untreated epilepsy in a rural community in Africa. Epilepsia, 1992; 33: 464-8.

26. Schoenberg, B.S.: Recent studies of the epidemiology of epilepsy in developing countries: a coordinated program for prevention and control. Epilepsia, 1978; 28(6): 721-2.

27. Ogunniyi, A., Osuntokun, B.O., Adeuja, A.O. et al,: Risk factors for epilepsy: Case-control study in Nigerians. Epilepsia, 1987; 28(3):280-5.

28. Danesi, M.A.: Classification of the epilepsies: An investigation of 945 patients in a developing country. Epilepsia, 1985: 26(2): 131-36.
29. Chadwick, D.W.: Diagnosis of Epilepsy. Lancet, 1990; 336: 291-5.

30. Gardiner, R.M.: Genetic approaches to basic mechanisms of epilepsy. J. Neurol, 1994; 241 (suppl 1) S82.

31. Jennings, M.T. and Bird, T.D.: Genetic influence in the epilepsies: Review of the literature with practical implications. Am. J. Dis. Child, 1981; 135: 450-7.

32. Doose, H., Gerken H., Horstmann. $F$ et al: Genetic factors in spikewave absences. Epilepsia, 1973; 14: 57-75.

33. Ogunrin, A.O. Adeyekun AA, Akhigbe A, Ofovwe C. (2005) Tuberous sclerosis in a Nigerian male: case report and review of literature. Discovery and Innovation (African Academy of Science), 17 (3/4): 122-128.

34. Metrakos, J.D. and Metrakos, K.: Genetics of convulsive disorders. II.: Genetic and electroencephalographic studies in centrencephalic epilepsy. Neurology 1961; 11: 474-83.

35. Doose, H., Gerken H., HienVolpel, F.K. et al.: Genetics of photosensitive epilepsy. Neuropaediatrics, 1969; 1: 56-73.

36. Dada, T.O.: The epilepsies: the incidence and causation in Nigeria. Medecine d'Afrique Noire, 1976. 1976; 23(5): 32029.

37. Rimoin, D.L. and Metrakos, J.D.: The genetics of convulsive disorders in the families of hemiplegics. Proc. Sci. and International Congress in Human Genetics, 1962; 1655-1658. 
38. Editorial Newsdesk - Africa Health. 1996; 18(20): 5.

39. Commission on Tropical Diseases of the International League Against Epilepsy. Relationship Between Epilepsy and Tropical Diseases. Epilepsia, 1994; 35(1): 89-93.

40. Zoli A., Shey-Njila O., Assana E., et al: Regional status, epidemiology and impact of Taenia solium cysticercosis in Western and Central Africa. Acta Trop. 2003; 87(1): 35-42.

41. Balogou A.A., Grunitzky K.E., Beketi K.E., et al: Cysticercosis and epilepsy in the city of Tone, north of Togo. Rev Neurol (Paris). 2000; 156(3): 270-3.

42. Commission on Classification and Terminology, International League Against Epilepsy. Proposed revisions of clinical and electroencephalographic

classification of epileptic seizures. Epilepsia, 1981; 22: 480-501.

43. Akanji, A.O., George, A.O., Olasode, B.J. et al. Insulinoma: a case report. East Afr. Med. J. 1992; 69(2): 117-9.

44. Adamolekun, B.: Seizures associated with chloroquine therapy. Cent Afr. J Med., 1992; 38(8): $350-2$.

45. Ahmed, M.H. and Obembe, A.: Electroencephalographic abnormalities in 351 Nigerians with epilepsy. West Afr. J. Med., 1991; 10: (3-4): 216-21.

46. Aicardi, J. and Chevrie, J.J.: Atypical benign partial epilepsy in childhood. Dev. Med. Child Neurology, 1982; 24: 281-92.
47. Holmes, G.L.: Partial seizures in children. Paedriatics, 1986; 77: 725-31.

48. Servit, Z., Machek, J. Stercova, A et al: Reflex influences in the pathogenesis of epilepsy in the light of clinical statistics. Epilepsia, 1962; 3: 315-22.

49. Jeavons, P.M.: Photosensitive epilepsy. In Laidlow, J. and Richens, A. (eds). A Texbook of Epilepsy. Edinburgh. Churchill Livingstone, 1982 pp 195-211.

50. Danesi, M.A.: Seasonal variation in the incidence of photo-paroxysmal response to stimulation among photosensitive epileptic patients: evidence from repeated EEG recordings. J. Neurol. Neurosurg. psychiatry, 1988; 51(6); 875-7.

51. Bickford, R.G., Whelan, J.L., Klass, D.W., et al: Reading epilepsy: Clinical and electroencephalographic studies of a new syndrome. Trans. Am. Neurol. Assoc., 1957; 81: 100-2.

52. Binnie, C.D.: Electroencephalography and epilepsy. In Hopkins, A. (eds). Epilepsy. Chapman and Hall, London, 1987 pp 169-199.

53. Danesi, M.A.: Electroencephalographic manifestation of grand mal epilepsy in Africans. Observation of relative rarity of interictal abnormalities. Epilepsia, 1988; 29:440-5.

54. Falope, Z.F., Ogunniyi, A., Osuntokun, B.O.: Factors associated with epileptiform EEG patterns in Nigerian epileptics. East Afr. Med. J., 1993; 70(5): 294-6. 
55. Osuntokun, B.O. and Bademosi, O.: EEG Correlates of epilepsy in Nigerians. Medecine d'Afrique Noire, 1976; 23(5): 337.

56. Gaustaut, H.: Computerized Transverse Axial Tomography in epilepsy. Epilepsia, 1976; 17: 337-8.

57. Shorvon, S.: Imaging in the Investigation of Epilepsy. In Hopkins, A. (eds) Epilepsy Chapman and Hall, London. 1987. pp 201-228.

58. So, E.L. and Penry, J.K.: Epilepsy in adults Ann Neurol. 1981; 9: 3-

59. Obajimi M.O., Fatunde O.J., Ogunseyinde A.O., et al: Computed tomography and childhood seizure disorder in Ibadan. West Afr J Med. 2004; 23(2): 167-72.

60. Ogunniyi, A., Adeyinka, A., Fagbemi, S.O. et al: Computerized tomographic findings in adolescent and adult Nigerian epileptics. West Afr. J. Med., 1994; 13(2): 128-31.

61. Brodie, M.J. and Ditcher, M.A.: Antiepileptic drugs. N. Eng J. Med., 1996; 334(3): 168-75.

62. Piachaud, J.: Untreated epilepsy? Letters - Africa Health: 1996; 18(2): 40.

63. Danesi M.A., Adetunji J.B. Use of alternative medicine by patients with epilepsy: a survey of 265 epileptic patients in a developing country. Epilepsia. 1994; 35(2): 344-51.

64. Mattson, R.H., Crammer, J.A., Collins, J.F. et al: Comparison of carbamazepine, phenobarbital, phenytoin and primidone in partial and secondarily generalized tonic-clonic seizures. N. Eng. J. Med. 1985; 313: 145-51.

65. Richens, A., Davidson, D.L.W., Cartlidge, N.E.F. et al: A multicentre comparative trial of sodium valproate and carbamazepine in adult onset epilepsy. J. Neurol. Neurosurg Psychiatric 1994; 57: 682-7.

66. Familusi, J.B.: Preliminary Nigerian experience in the use of carbamazepine in children with intractable seizures. Epilepsia, 1985; 26(1): 10-14.

67. Sykes R.M. Epilepsy in children in Benin City, Nigeria. Ann Trop Paediatr. 2002; 22(3): 287-96.

68. Ogunniyi, A. and Osuntokun, B.O.: Effectiveness of anticonvulsant therapy in the epilepsies in Nigerian Africans. East Afr. Med. J. 1991; 68(9): 707-13.

69. Ogunrin, AO, Adamolekun A, Ogunniyi A. Cognitive side effects of anti-epileptic drugs in Nigerians with epilepsy. African Journal of Neurological Sciences. 2005; 24 (1): $18-24$.

70. Specht, U., Boenigk, H.E., Wolf, P.: Discontinuation of clonazepam after long-term treatment. Epilepsia, 1989; 30: 458-63.

71. Beghi, E., di Mascio, R. Tognoni, G: Drug treatment of epilepsy: Outlines, Criticism and Perspectives. Drugs, 1986; 31: 249-65.

72. McGuire, A.M., Duncan, J.S., Trimble, M.R.: Effects of vigabatrin on cognitive function 
and mood when used as addon therapy in patients with intractable epilepsy. Epilepsia, 1992; 33(1): 128-34.

73. Tassinari, C.A., Michelucci, R., Ambrosetto, G. et al: A doubleblind study of vigabatrin in the treatment of drug-resistant epilepsy. Arch. Neurol., 1987; 44: 907-10.

74. Meldrum, B.S. and Porter, R.J.: Current Problems in Epilepsy: 4 New anticonvulsant drugs. John Libbey, London, 1986.

75. Medical Research Council Antiepileptic Drug Withdrawal Study Group: Randomised Study of antiepileptic drug withdrawal in remission. Lancet, 1991; 337: 1175-80.

76. Hopkins, A.: The surgical management of epilepsy. In Epilepsy. Chapman and Hall. Cambridge, 1987 pp 283-99.

77. Geoffroy, G., Lassonde, M., Delistle, F. et al: Corpus callostomy for control of intractable epilepsy in children. Neurology, 1983; 33: 891-7.

78. Spencer, S.S., Spencer, D.D., Glaser, G.H., et al: More intense focal seizure type after callosal section: the role of inhibition. Ann Neurol., 1984; 16: 686-93.

79. Cooper, I.S.: Effect of chronic stimulation of anterior cerebellum on neurological diseases. Lancet, 1973; 1: 206.
80. Wieser H.G. Silfvenius H. Overview: epilepsy surgery in developing countries. Epilepsia. 2000; 41 Suppl 4: S3-9.

81. Wilder, R.M.: The effect of ketonuria on the course of epilepsy. Mayo Clin Bull, 1921; 2: 307.

82. Schwartz, R.H., Eaton, J., Aynsley-Green, A., et al: Ketogenic diets in the management of epilepsy. In 'Research Progress in epilepsy' (ed. Clifford Rose) 1983. Pitman. London pp 326-32.

83. Imam I., Talabi O.A., Sanya E.O., et al.: The quality of life of chronic epileptic patients in Ibadan, Nigeria. Afr J Med Med Sci. 2003; 32(4): 367-9.

84. Ogunrin A.O., Adamolekun B., Ogunniyi A., Aldenkamp, A.P. Cognitive functions in newly diagnosed Nigerians with epilepsy. Can J Neurol Sci. 2000; 27 (2):148 -151.

85. Ogunrin A.O., Adamolekun B., Ogunniyi A., et al.: Seizure frequency and cognitive performances of Nigerian epileptic patients. J Med Biomed Res. 2003; 2: 53-60.

86. Ojinaka, N.C. Teachers' perception of epilepsy in Nigeria: a community-based study. Seizure. 2002; 11(6):386-91. 